\title{
Previous Institutionalization Is Followed by Broader Amygdala-Hippocampal-PFC Network Connectivity during Aversive Learning in Human Development
}

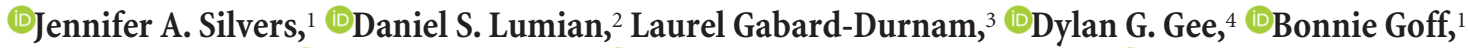 \\ Dominic S. Fareri, ${ }^{5}{ }^{-}$Christina Caldera, ${ }^{1}$ Jessica Flannery, ${ }^{6}$ Eva H. Telzer, ${ }^{7}$ Cathryn L. Humphreys, ${ }^{8}$ \\ and ${ }^{-N i m}$ Tottenham ${ }^{3}$ \\ ${ }^{1}$ Department of Psychology, University of California, Los Angeles, Los Angeles, California 90095, ${ }^{2}$ Department of Psychology, University of Denver, Denver, \\ Colorado 80208, ${ }^{3}$ Department of Psychology, Columbia University, New York, New York 10027, ${ }^{4}$ Sackler Institute for Developmental Psychobiology, Weill \\ Cornell Medical College, New York, New York 10065, ${ }^{5}$ Department of Psychology, University of Oregon, Eugene, Oregon 97403, ${ }^{6}$ Gordon F. Derner Institute \\ of Advanced Psychological Studies, Adelphi University, Garden City, New York 11530, ’Department of Psychology, University of Illinois at Urbana- \\ Champaign, Champaign, Illinois 61820, and ${ }^{8}$ Department of Psychology, Stanford University, Stanford, California 94305
}

Early institutional care can be profoundly stressful for the human infant, and, as such, can lead to significant alterations in brain development. In animal models, similar variants of early adversity have been shown to modify amygdala-hippocampal-prefrontal cortex development and associated aversive learning. The current study examined this rearing aberration in human development. Eighty-nine children and adolescents who were either previously institutionalized (PI youth; $N=46 ; 33 \mathrm{females}$ and 13 males; age range, $7-16$ years) or were raised by their biological parents from birth $(N=43 ; 22$ females and 21 males; age range, 7-16 years) completed an aversive-learning paradigm while undergoing functional neuroimaging, wherein visual cues were paired with either an aversive sound $(\mathrm{CS}+)$ or no sound (CS-). For the PI youth, better aversive learning was associated with higher concurrent trait anxiety. Both groups showed robust learning and amygdala activation for CS + versus CS - trials. However, PI youth also exhibited broader recruitment of several regions and increased hippocampal connectivity with prefrontal cortex. Stronger connectivity between the hippocampus and ventromedial PFC predicted significant improvements in future anxiety (measured 2 years later), and this was particularly true within the PI group. These results suggest that for humans as well as for other species, early adversity alters the neurobiology of aversive learning by engaging a broader prefrontal-subcortical circuit than same-aged peers. These differences are interpreted as ontogenetic adaptations and potential sources of resilience.

Key words: early life stress; fMRI; learning; neurodevelopment; threat

\section{Significance Statement}

Prior institutionalization is a significant form of early adversity. While nonhuman animal research suggests that early adversity alters aversive learning and associated neurocircuitry, no prior work has examined this in humans. Here, we show that youth who experienced prior institutionalization, but not comparison youth, recruit the hippocampus during aversive learning. Among youth who experienced prior institutionalization, individual differences in aversive learning were associated with worse current anxiety. However, connectivity between the hippocampus and prefrontal cortex prospectively predicted significant improvements in anxiety 2 years following scanning for previously institutionalized youth. Among youth who experienced prior institutionalization, age-atypical engagement of a distributed set of brain regions during aversive learning may serve a protective function.

\section{Introduction}

Converging cross-species evidence suggests that early adversity alters the structure and function of brain regions involved in aversive learning, including the amygdala, hippocampus, and medial prefrontal cortex (mPFC; Mirescu et al., 2004; Roceri et al., 2004; Blaise et al., 2008; Ono et al., 2008; Mehta et al., 2009;
Spinelli et al., 2009; Tottenham et al., 2010; Uchida et al., 2010; Jackowski et al., 2011; Tottenham et al., 2011; Gee et al., 2013; Luby et al., 2013; Malter Cohen et al., 2013; Pagliaccio et al., 2014; McEwen et al., 2016). Although it is known that early adversity alters the neural bases of aversive learning and predicts anxiety in adults (Bremner et al., 2005; Bagot et al., 2009; Kessler et al., 2010; 
Gorka et al., 2014), little is known about how it impacts aversive learning during human development. This limits our understanding of how early adversity begets adult anxiety.

Numerous nonhuman animal studies have manipulated early adversity by reducing maternal care, which is a potent stressor for altricial infants whose survival depends on the caregiver, with maternal separation or insufficient bedding paradigms (Roth and Sullivan, 2005; Malter Cohen et al., 2013; Callaghan et al., 2014). Such studies commonly use aversive-learning paradigms (Moriceau and Sullivan, 2006; Ono et al., 2008; Callaghan and Richardson, 2011) both because aversive learning is a standard for assessing amygdala-hippocampal-mPFC function and because of its translational significance for anxiety (Mineka and Oehlberg, 2008; Maren et al., 2013). Juvenile animals rely exclusively on the amygdala for aversive learning (Kim et al., 2012; Li et al., 2012). During adolescence, striking changes in amygdalahippocampal-mPFC connectivity are observed (Pattwell et al., 2011), and, by adulthood, aversive learning is supported by strong interconnections among the amygdala, hippocampus, and mPFC in nonhuman animals (LeDoux et al., 1990; Corcoran and Quirk, 2007; Sierra-Mercado et al., 2011) and human adults (Fullana et al., 2016; Greco and Liberzon, 2016). Rodent models have revealed that maternal separation leads to precocious prefrontal and hippocampal maturation (Huang et al., 2005; Muhammad et al., 2012), and adult-like aversive learning and anxiety during development (Moriceau and Sullivan, 2006; Ono et al., 2008; Callaghan and Richardson, 2011). Importantly, while maternal deprivation accelerates aversive-learning processes, it may slow or impair cognitive development (Hulshof et al., 2011), suggesting that stress-induced changes are not uniform. This is in line with broader evidence suggesting that cognitive and emotional trajectories are not uniform in typical or atypical development (Reichenberg et al., 2010).

The first question the present study addressed was whether early adversity, in the form of prior institutionalization, alters the neurobiology of aversive learning during human development. Previously institutionalized (PI) youth (i.e., youth who were initially reared in orphanage care) experience parental deprivation along with other stressors, such as a lack of sensory stimulation. Given evidence from animal models that early caregiving adversity accelerates amygdala, hippocampal, and medial prefrontal development (Callaghan et al., 2014), we hypothesized that aversive learning would be supported by a more distributed, adultlike set of brain regions in PI youth relative to comparison youth.

The second question that the current study addressed was whether differences in aversive learning might partially explain the association between early institutionalization and anxiety. Extensive prior work has examined associations between aversive learning and anxiety (Mineka and Oehlberg, 2008; Indovina et al., 2011; Britton et al., 2013; Torrents-Rodas et al., 2013; Cohen Kadosh et al., 2015) and early adversity (Callaghan et al., 2014).

\footnotetext{
Received Jan. 5, 2016; revised May 4, 2016; accepted May 7, 2016

Author contributions: N.T. designed research; D.S.L., L.G.-D., D.G.G., B.G., D.S.F., C.C., J.F., E.H.T., K.L.H., and N.T. performed research; J.A.S., D.S.L., and N.T. analyzed data; J.A.S. and N.T. wrote the paper.

This research was supported by National Institutes of Health Grant R01-MH-091864 and Dana Foundation Grant P50MH078105.

The authors declare no competing financial interests.

Correspondence should be addressed to either of the following: Jennifer A. Silvers, Department of Psychology, University of California, Los Angeles, 1285 Franz Hall, Box 951563, Los Angeles, CA 90095, E-mail: silvers@ucla.edu; or Nim Tottenham, Department of Psychology, Columbia University, 406 Schermerhorn Hall, 1190 Amsterdam Avenue, Mail Code 5501, New York, NY 10027, E-mail: nlt7@columbia.edu.

DOI:10.1523/JNEUROSCI.0038-16.2016

Copyright $\odot 2016$ the authors $\quad 0270-6474 / 16 / 366421-11 \$ 15.00 / 0$
}

Table 1. Demographic characterization of the sample

\begin{tabular}{|c|c|c|c|}
\hline Variable & $\mathrm{PI}$ group $(n=46)$ & $\begin{array}{l}\text { Comparison group } \\
(n=43)\end{array}$ & Statistic \\
\hline Sex & 33 female; 13 male & 22 female; 21 male & $\begin{aligned} \chi_{(1)}^{2} & =3.986 \\
p & =0.046\end{aligned}$ \\
\hline Age $(\text { years) })^{a}$ & $12.35(2.56) ; 7.58-16.42$ & $11.83(3.27) ; 7.08-16.92$ & $\begin{aligned} t_{(87)} & =0.833, \\
p & =0.407\end{aligned}$ \\
\hline $10^{a}$ & 104.80 (15.82); $69-142$ & $112.86(16.09) ; 84-146$ & $\begin{aligned} t_{(87)} & =1.439, \\
p & =0.15\end{aligned}$ \\
\hline Pubertal status $^{b}$ & $2.48(0.85) ; 1-4$ & $2.20(0.80), 1-3.6$ & $\begin{aligned} t_{(73)} & =2.381, \\
p & =0.019\end{aligned}$ \\
\hline Origin & $\begin{array}{l}1 \text { Africa, } 4 \text { Central America, } \\
17 \text { East Asia, } 1 \text { South Asia, } \\
21 \text { Europe, } 2 \text { unknown }\end{array}$ & & \\
\hline $\begin{array}{l}\text { Age adopted } \\
\text { (months) }^{a}\end{array}$ & $31.40(30.10) ; 3-120$ & & \\
\hline
\end{tabular}

${ }^{a}$ Values reported as mean (SD); range.

${ }^{b}$ Puberty was assessed using the Pubertal Scale of Development (parent report) and was obtained for 41 Pl youth and 34 comparison youth.

Anxious adults exhibit enhanced aversive learning, but weak discrimination learning (Lissek et al., 2005) and compromised hippocampal function (Kheirbek et al., 2012), whereas in development, early adversity accelerates hippocampal development (Huang et al., 2005) and anxiety is associated with better discrimination learning (Jovanovic et al., 2014). Given evidence that neural adaptations to caregiving adversity can be anxiolytic (Gee et al., 2013), it was hypothesized that altered amygdala-hippocampal-mPFC function during aversive learning would predict reduced anxiety among PI youth.

\section{Materials and Methods}

\section{Participants}

Forty-six PI youth ( 33 females and 13 males; age range, $7.58-16.42$ years; mean age, 12.35 years; SD age, 2.56 years) and 43 comparison youth $(22$ females and 21 males; age range, $7.08-16.92$ years; mean age, 11.83 years; SD age, 3.27 years), who were raised from birth by their biological parents, participated in the present study. Demographic information, including the country of origin for PI youth, is reported in Table 1. All participants were currently residing in the United States at the time of testing, and all research was completed at the University of California, Los Angeles (UCLA). This study was approved by the UCLA Institutional Review Board. All participants provided informed assent, and their parents provided informed consent.

The results presented here are part of a larger study examining the neural bases of emotional development, and the participants included in the present analyses represent a subset of this larger sample. For the present analyses, only data from participants 7-16 years of age, the age range with maximal overlap between the PI and comparison groups, were analyzed. From this subsample of 106 participants, 1 participant (a male comparison participant, 16.98 years of age) was excluded because of poor behavioral performance (i.e., the participant did not make responses on the task) and 16 participants (five PIs: 4 females and 1 male; mean age, 10.63 years; 11 comparison participants: 4 females and 7 males; mean age, 9.96 years) were excluded for excessive head motion (as described below, this was established as participants with $>20 \%$ of volumes having absolute motion exceeding $2.5 \mathrm{~mm}$ or average framewise displacement exceeding $0.9 \mathrm{~mm}$ ), which resulted in the ultimate sample of 89 participants.

\section{Assessment of anxiety}

Baseline anxiety symptomology. All parents of PI participants and all but one parent of comparison participants completed the Screen for Child Anxiety Related Disorders (SCARED) before scanning (Birmaher et al., 1999). While the SCARED is designed for youth $8-18$ years of age, it was deemed an appropriate measure for the present sample because the vast majority of participants ( 83 of 89 ) fell within this age range, and the 


\section{A Paradigm}
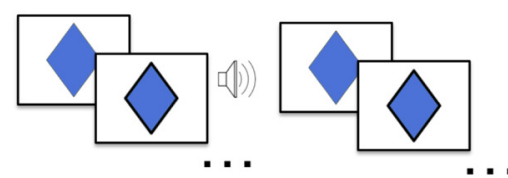

$\mathrm{CS}+$ (reinforced) $\mathrm{CS}+$ (unreinforced) Block

Block

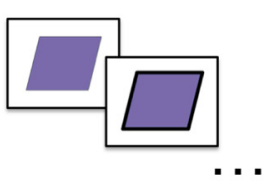

CS- Block
B Behavior

Main effect of stimulus type*

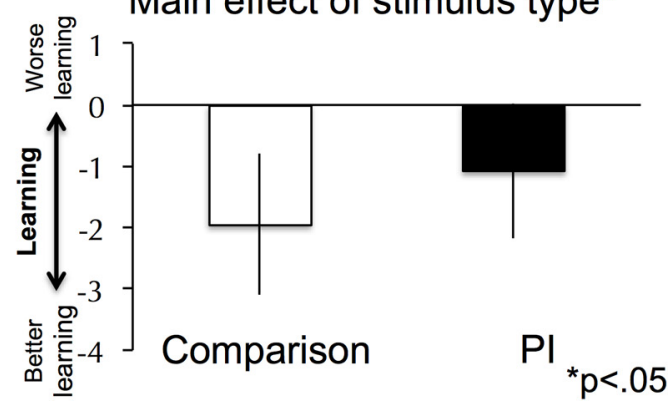

Figure 1. Aversive-learning paradigm and behavior. A, Participants completed blocks of unreinforced $C S+$, reinforced $C S+$, and $C S-$ trials. $B$, Participants responded more quickly over time for unreinforced $C S+$ than $C S-$ trials, shown here as Slope $_{C S+}-S_{\text {lope }} \mathrm{CS}_{-}$. All error bars reflect between-subjects SE.

SCARED is an effective, well validated tool for screening for anxiety in youth (Simon and Bögels, 2009). The SCARED is a 41 item questionnaire that probes anxiety symptomology (e.g., "My child gets scared if she sleeps away from home"), with answer options ranging from 0 to 2 ("not true" to "very true"). The range of possible scores on the SCARED is $0-82$, with higher scores suggesting greater levels of anxiety. Parents of both comparison participants (mean age at scanning, 11.74 years; SD, 3.19 years) and PI participants (mean age at scanning, 12.08 years; SD, 2.57 years) were asked to complete this measure. The total SCARED score was used for analyses.

Longitudinal changes in anxiety symptomology. Parents were asked to complete the SCARED $\sim 2$ years after the initial scanning session (mean time elapsed between testing sessions: PI group, 22.14 months; comparison participants, 23.07 months), and 21 parents of PI participants and 27 parents of comparison participants complied. The PI youth who participated in the 2 year follow-up did not differ from the PI youth who did not participate in terms of age $\left(t_{(44)}=0.64, p=0.52\right)$ or baseline anxiety $\left(t_{(44)}=0.64, p=0.53\right)$. Similarly, comparison youth who participated in the 2 year follow-up did not differ from comparison youth who did not participate in the 2 year follow-up in terms of age $\left(t_{(41)}=0.25, p=0.81\right)$ or baseline anxiety $\left(t_{(40)}=0.007, p=0.995\right)$. A univariate GLM analysis incorporating PI group, mean-centered age, mean-centered baseline SCARED scores, sex, time between testing sessions, and the PI $\times$ baseline SCARED interaction term was conducted to predict longitudinal changes in SCARED scores. This revealed that higher baseline SCARED scores were associated with greater decreases in anxiety ( $\beta$ estimate for effect $\left.=-0.25 ; F_{(1,41)}=9.8, p<0.005\right)$. Additionally, PI group predicted changes in anxiety over time $\left(F_{(1,41)}=4.48, p<0.05\right)$, such that comparison participants showed greater decreases in anxiety (mean change in anxiety, adjusted for covariates, -5.80 ) than did individuals in the PI group (mean change in anxiety, adjusted for covariates, -1.35 ). All other predictors were nonsignificant $(p>0.24)$. Because time between testing sessions did not predict changes in anxiety $\left(F_{(1,41)}=1.39\right.$, $p=0.24)$, and was not central to hypotheses, it was not included in subsequent analyses.

\section{Experimental task}

Participants completed an aversive-learning task while inside of an MRI scanner. This task was an adapted version of a traditional threatdiscrimination learning task that included an escape parameter that provided a behavioral index of learning. Participants were instructed to press a button as soon as they saw the border of the shape [visual cue paired with an aversive sound (CS+) or visual cue paired with no sound (CS-)] thicken, which coincided with the onset of the unconditioned stimulus (US) for reinforced CS + trials (Fig. 1A). Though participants were not told so, the button press terminated each trial and temporarily extinguished the US. Thus, learning was indexed by whether participants responded more quickly to CS + than CS - trials over the course of each block of trials. While skin conductance responses (SCRs) are commonly used to assess aversive learning in humans, often a sizable minority of participants do not show SCRs or do not distinguish between the CS+ and CS-, resulting in a reduction in sample size (Pattwell et al., 2012), particularly in neuroimaging studies where the scanner noise can distort the SCR (Knight and Wood, 2011). As such, escape learning (as indexed by reaction times; see below) was used in lieu of SCR. Current theory distinguishes the kind of escape learning used in the present task from active avoidance paradigms as respectively occurring before and after encountering a US (Mobbs et al., 2015). In other words, in active avoidance paradigms certain cues or actions can prevent a US from occurring, whereas in escape from threat paradigms such as the one used in the present task, certain cues or actions allow one to extinguish the US but not to avoid it altogether. Various escape-learning paradigms have been used in animal (Mowrer and Lamoreaux, 1946; Cain and LeDoux, 2007) and human research (Penney and Kirwin, 1965), and are a robust means of assessing conditioned responses (McAllister and McAllister, 1962).

On each trial, participants viewed one of two shapes. Each shape initially had a thin border that became thick after $1000 \mathrm{~ms}$. Participants were instructed to make a button response when the border changed (Fig. 1A), which was synchronized with an aversive noise (Neumann et al., 2008; US) on reinforced CS + trials (see below for further description of the US). The US and CS + coterminated when participants responded and another trial immediately began. Participants completed eight $27 \mathrm{~s}$ task blocks (three reinforced CS+ blocks, three unreinforced CS + blocks, and two CS - blocks). A block design was used to maximize statistical power while limiting scanning time, given the young age of some participants. Assignment of CS+ and CS - to shape was counterbalanced across participants. All analyses presented in this manuscript compared unreinforced CS+ and CS - trials.

The US was a loud, metallic, high-frequency noise (Neumann et al., 2008) that was titrated for each participant before the task so that it was perceived as "annoying" but not painful (maximum volume, $65 \mathrm{~dB}$ ). To confirm the aversive quality of the US, a subset of PI and comparison participants rated it on a scale of $1-9$ at a separate testing session $(1=$ do not like at all/really bad, $5=$ neutral, $9=$ like it a lot $/$ really good). Twenty-four PI participants (mean age, 11.60 years; SD, 2.49 years) and 32 comparison participants (mean age, 11.20 years; SD, 3.23 years) provided these ratings. Overall, participants rated the noise as significantly worse than neutral (neutral $=5$; mean rating of $\mathrm{US}=3.61$; $\mathrm{SD}=2.58$; $\left.t_{(55)}=4.03 ; p<0.001\right)$. PI and comparison participants did not differ significantly in how aversive they found the noise to be $\left(t_{(54)}=1.09, p=\right.$ $0.28)$, nor did ratings differ across age $(r=-0.10, p=0.44)$.

\section{Behavioral data analysis}

It was hypothesized that participants would learn that responding to the CS + cue extinguished the US, and thus reaction times (RTs) would speed up for CS + trials but not for CS - trials. RTs during the first two blocks of the unreinforced CS + and CS - blocks were compared (while there were two CS - and three CS + blocks, comparing the first two CS+ blocks to the two CS - blocks allowed for comparison on a comparable time scale). To calculate the change in learning over time, RTs for each condition and each participant were fitted using linear regression, and the $\beta$-coefficients (i.e., slopes) for each condition and each participant 
were computed. Two steps were taken to reduce the effects of outliers on slope calculations. First, before computing slopes for each individual, trials with RTs $>5000 \mathrm{~ms}$ were removed. Second, slopes were winsorized such that slopes below the fifth percentile (collapsed across groups) replaced by the slope value at the fifth percentile (CS,--7.46 ; CS + , -14.20 ), and slopes above the 95th percentile were replaced by the slope value at the 95th percentile (CS-, 14.93; CS+, 8.37). RT slopes for CSand unreinforced CS+ conditions were entered into a repeatedmeasures ANOVA in SPSS along with mean-centered age, group (PI group vs comparison group), and the age $\times$ group interaction term. Mean-centered average RTs and sex were entered as additional covariates of no interest.

\section{fMRI data acquisition and analysis}

Acquisition. Whole-brain imaging data were collected on a $3 \mathrm{~T}$ Siemens Magnetom Trio scanner using a standard radiofrequency 12-channel head coil. For each participant, a whole-brain high-resolution, $\mathrm{T}^{\star}{ }_{-}$ weighted anatomical scan (MPRAGE; $256 \times 256$ in-place resolution; 256 $\mathrm{mm}$ FOV; $192 \times 1 \mathrm{~mm}$ sagittal slices). The task was completed in a single functional scan. T2*-weighted echoplanar images (interleaved) were collected at an oblique angle (range, $\sim 10-30^{\circ}$; 154 volumes/run; TR, 2000 $\mathrm{ms}$; TE, $30 \mathrm{~ms}$; flip angle, $90^{\circ}$; matrix size, $64 \times 64$; FOV, $192 \mathrm{~mm}$; 34 slices; 4-mm-thick contiguous slices).

Preprocessing. Preprocessing was conducted with the Analysis of Functional NeuroImages (AFNI) software package (Cox, 1996). The first four volumes for each participant were discarded to allow for scanner signal stabilization. Functional data were slice time corrected, registered to the minimum outlier volume of the run (realignment), spatially smoothed with a $6 \mathrm{~mm}$ Gaussian kernel (FWHM), and the percentage signal change was calculated. Finally, high-resolution (MPRAGE) structural scans were transformed into Talairach space (Talairach and Tournoux, 1988), and the functional data were moved into Talairach space using each participant's Talairach-transformed MPRAGE scan parameters (alignment between the anatomical and functional scans was assessed visually). Functional data that appeared misaligned were corrected with rigid-body transformation.

Steps taken to remove motion-related artifacts. Participants participated in a mock scanning session, so that they could become familiar with scanning procedures and receive feedback on staying still while scanning. Additionally, individual volumes containing motion exceeding $2.5 \mathrm{~mm}$ absolute displacement in any direction or $>0.9 \mathrm{~mm}$ frame-to-frame displacement were censored (i.e., removed) from further analyses. Individual participants who had $>20 \%$ ( 15 volumes) censored through either criterion were removed from analyses, and the remaining sample had an average of $2.63 \%$ (3.97 volumes) censored. A repeated-measures ANOVA was conducted using PI group, sex, mean-centered age, and the PI group $\times$ mean-centered age interaction term as between-subject predictors, and the number of censored volumes for the CS+ and CSconditions as within-subject predictors. A main effect of age was observed such that older participants had significantly fewer censored volumes overall $\left(F_{(1,84)}=7.85, p<0.01\right)$. Consequently, average head motion was included as a covariate at the group level in all wholebrain analyses [as well as for analyses using a region of interest (ROI) approach and small volume correction]. A condition $\times$ group $\times$ age interaction $\left(F_{(1,84)}=5.11, p<0.05\right)$ was observed, and follow-up correlational analyses revealed that this was driven by age predicting significantly fewer censored volumes for the CS + condition in comparison youth $(r=-0.47, p<0.005)$ but not for any other group/ condition combinations $(p>0.10)$. No other predictors were significantly associated with the number of censored volumes $(p>$ 0.09 ). Standard realignment procedures were used during preprocessing to correct for head motion, and motion parameters were included as regressors of no interest.

Individual and group-level fMRI analyses. Separate regressors for the CS + reinforced, CS + unreinforced, and CS - blocks of stimuli were convolved with the hemodynamic response function using the AFNI dmBLOCK function. Six motion regressors $(x, y$, and $z$ displacement; pitch, roll, and yaw rotation) and their derivatives were included as co- variates, and orthogonalized linear, quadratic, and cubic trends were modeled to control for drift.

$3 \mathrm{dttest}++$ was used to examine task and group effects. Group (PI vs comparison), mean-centered age, mean-centered average framewise displacement, sex, and the group $\times$ age interaction term were used as predictors for unreinforced CS + and CS - blocks. For each subject, smoothness estimates of the residuals were calculated, and the group average of these estimates $(7.825,7.796$, and 7.419$)$ were input into $3 \mathrm{dClustSim}$. Maps were initially thresholded at $p<0.005$, uncorrected, masked using the AFNI TT_N27_caez gray matter mask, which is derived from the Eickhoff Anatomy Toolbox (Eickhoff et al., 2005), and then were corrected at the cluster level to achieve a corrected $p<$ 0.05 , as estimated by $3 \mathrm{dClustSim}(k=38$ voxels, all voxels sharing at least one side).

Given a priori hypotheses about the amygdala and the hippocampus, bilateral amygdala and hippocampal ROIs were taken from the Harvard Oxford Atlas in FSL and warped to Talairach space. Clusters within these ROIs were thresholded to achieve a small volume corrected $p$ value of $<0.05$ (six voxels for the hippocampus, four voxels for the amygdala), as determined by $3 \mathrm{dClust}$ Sim.

Functional connectivity. Two psychophysiological interaction (PPI) analyses were conducted (Friston et al., 1997). In both analyses, six standard head motion parameters and their derivatives were included as covariates, and separate regressors (generalized PPI) were made for the seed region time course, as well as the interaction between the seed region time course and the CS+ (unreinforced), CS+ (reinforced), and CSconditions. Orthogonalized linear, quadratic, and cubic trends were modeled to control for drift.

First, a PPI analysis was performed to examine amygdala-based connectivity in PI and comparison youth. As described in the Results, the left (13 voxels; Talairach coordinates: $-16,-1,-13$ ) and right (7 voxels; Talairach coordinates: $23,2,-13$ ) amygdala ROIs were identified by the $\mathrm{CS}+>\mathrm{CS}-$ contrast, and were thresholded using small volume correction. This bilateral amygdala ROI was used as a seed, and mean-centered age, group (PI vs comparison), mean-centered average frame-to-frame displacement, average signal intensity in white matter, sex, and the age $\times$ group interaction term were included as predictors in the PPI.

Second, a PPI analysis was performed to examine hippocampal-based connectivity in PI and comparison youth. The right hippocampal ROI defined by the group $(\mathrm{PI} \times$ comparisons $) \times$ task condition $(\mathrm{CS}+>$ CS-) interaction (thresholded using small volume correction, as described above) was used as the seed (six voxels; Talairach coordinates: $29,-31,-4)$. Mean-centered age, group (PI vs comparison), meancentered average frame-to-frame displacement, average signal intensity in white matter, sex, and the age $\times$ group interaction term were included as predictors in the PPI.

\section{Results}

\section{Behavioral results associated with aversive learning}

Effects of age, condition, and group

A repeated-measures ANOVA revealed that PI and comparison youth showed discrimination learning, as evidenced by a main effect of task on RT slopes across trials $\left(F_{(1,83)}=4.65, p<0.05\right.$; Fig. $1 B)$. Specifically, participants made faster responses over time on CS + trials (mean slope, adjusted for covariates, -1.06) and slower responses to CS - trials (mean slope, adjusted for covariates, 0.45$)$. Task condition did not interact with group, age, sex, or the group $\times$ age interaction term $(p>0.25)$. Age predicted more negative slopes in general, suggesting that older participants made increasingly fast responses over the course of the experiment, compared with younger participants $\left(F_{(1,83)}=4.01\right.$, $p<0.05)$.

\section{Relationships between learning and anxiety symptomology as a function of group}

To examine whether individual differences in learning (i.e., the difference in RT slopes for CS + and CS - trials) were associated with SCARED anxiety scores and whether this relationship was 


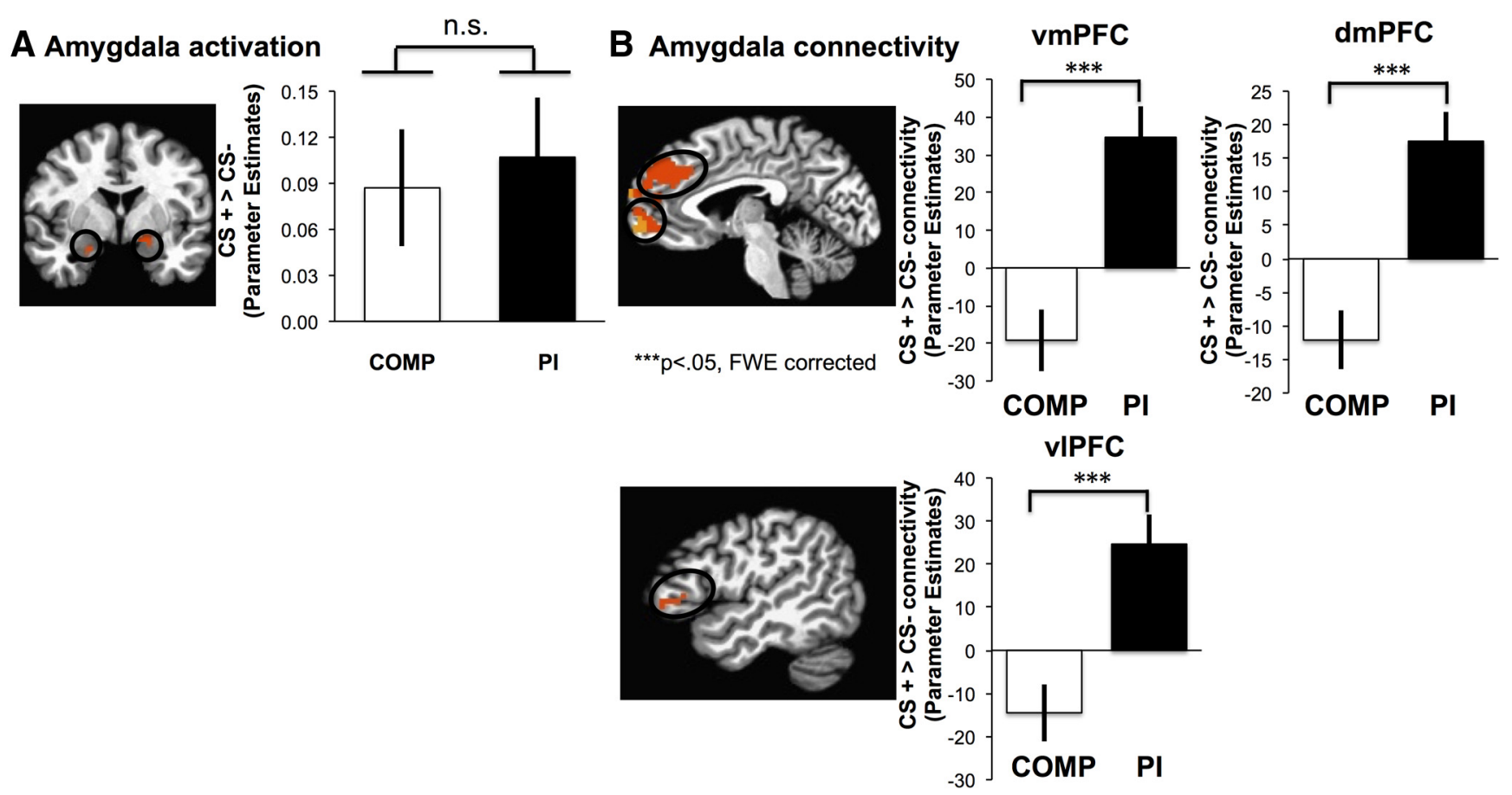

Figure 2. Amygdala activation and connectivity. $A$, The $C S+>C S-$ contrast revealed bilateral amygdala recruitment for both groups (contrast values were averaged for the left and right sides for simplicity of presentation). $\boldsymbol{B}$, Pl and comparison youth showed differential amygdala-prefrontal connectivity. All error bars reflect between-subjects SE.

moderated by group, a univariate GLM analysis was performed. Group, age (mean centered), sex, learning (mean centered), average reaction time (mean centered), and the group $\times$ learning interaction term were entered as predictors, and concurrent SCARED anxiety scores were entered as a dependent variable. Negative values for the CS + versus CS - RT slope contrast index increasingly fast RTs for CS + versus CS - trials and, thus, better learning. Group $\left(F_{(1,81)}=12.22, p=0.001\right)$ and the group $\times$ learning interaction term $\left(F_{(1,81)}=4.59, p<0.05\right)$ significantly predicted anxiety (see Fig. $3 c$ ). All other predictors were not significant $(p>0.07)$. Members of the PI group (mean, adjusted for covariates, 15.79) had more anxiety on average than members of the comparison group (mean, adjusted for covariates, 8.99). To formally examine how group influenced the relationship between learning and anxiety, a moderation analysis was conducted in SPSS. The moderation analysis revealed that, after accounting for the above described covariates, group significantly moderated $\left(R^{2}\right.$ increase due to interaction $\left.=0.04\right)$ the effect of learning on anxiety, such that better learning (i.e., negative values) predicted more anxiety in the PI group $(\beta=-0.42, p=0.01)$ but not in the comparison group $(\beta=0.14, p=0.50)$.

A parallel univariate GLM analysis was performed to examine whether individual differences in learning or group influenced longitudinal changes in anxiety over time. Just as before, group, age (mean centered), sex, learning (mean centered), average reaction time (mean centered), and the group $\times$ learning interaction term were entered as predictors, as well as baseline SCARED anxiety scores and the interaction between baseline SCARED anxiety scores and group. Change in SCARED anxiety scores was entered as the dependent variable. Higher baseline SCARED anxiety scores predicted steeper decreases in anxiety over time $\left(F_{(1,39)}=13.22, p=0.001\right)$, but the interaction between baseline anxiety and group was not significant $\left(F_{(1,39)}=1.13, p=0.29\right)$. The comparison group showed significantly greater decreases in anxiety over time than the PI group $\left(F_{(1,39)}=4.13, p<0.05\right)$, and there was a marginal interaction between group and learning such that better learning (i.e., more negative values) was associated with decreased anxiety 2 years later for the comparison participants, but not for PI youth $\left(F_{(1,39)}=4.04, p=0.051\right)$.

\section{Neuroimaging results associated with aversive learning}

Brain activation during aversive learning

Both groups recruited the bilateral amygdala (Fig. 2A) and dorsomedial prefrontal cortex (dmPFC) more strongly for CS + versus CS - trials (Table 2) The group $\times$ condition interaction revealed that PI youth showed stronger recruitment of the hippocampus for CS+ versus CS - trials than comparison youth (Table 2, Fig. 3A).

\section{Functional connectivity during aversive learning}

Amygdala connectivity. To examine amygdala connectivity during aversive learning, a whole-brain, generalized PPI analysis was performed using the bilateral amygdala cluster identified by the $\mathrm{CS}+>\mathrm{CS}-$ contrast as a seed region. Across both groups, connectivity between the hippocampus and the right superior frontal gyrus (SFG) differed significantly as a function of task condition (Table 3). Specifically, strong positive amygdala-SFG connectivity was observed for CS + trials, and negative connectivity was observed for CS - trials.

Group (PI vs comparison) and condition (CS+ vs CS-) interacted to predict connectivity between the amygdala and ventromedial PFC (vmPFC), dmPFC, and ventrolateral PFC (vlPFC; Fig. 2B, Table 3. Negative connectivity was observed for CStrials in PI youth for both vmPFC $\left(t_{(45)}=2.73, p<0.01\right)$ and $\operatorname{dmPFC}\left(t_{(45)}=2.55, p=0.01\right)$, but connectivity was not significantly different from zero for CS + trials $(p>0.50)$. Negative connectivity was observed between the amygdala and vmPFC $\left(_{(42)}=2.21, p<0.05\right)$ as well as the $\operatorname{dmPFC}\left(t_{(42)}=2.55, p<\right.$ $0.05)$ for CS + trials in comparison youth, while connectivity for $\mathrm{CS}-$ trials was significantly different from zero $(p>0.57)$. An 
Table 2. Brain regions showing differential activation during aversive learning

\begin{tabular}{|c|c|c|c|c|c|}
\hline \multirow[b]{2}{*}{ Region } & \multirow{2}{*}{$\begin{array}{l}\text { Voxels } \\
(n)\end{array}$} & \multirow{2}{*}{$t$} & \multicolumn{3}{|c|}{$\begin{array}{l}\text { Talairach } \\
\text { coordinates }\end{array}$} \\
\hline & & & $x$ & $y$ & $z$ \\
\hline $\begin{array}{l}\text { Main effect of task condition: } \mathrm{CS}+>\mathrm{CS}- \\
\mathrm{dmPFC} \text {, anterior cingulate cortex, right inferior } \\
\text { frontal gyrus, right middle frontal gyrus, right } \\
\text { superior frontal gyrus, right insula, right amygdala, } \\
\text { right middle and superior temporal gyri, } \\
\text { motor cortex, precuneus }\end{array}$ & 5829 & 4.27 & 2 & 65 & 20 \\
\hline $\begin{array}{l}\text { Left middle and superior temporal gyri, } \\
\text { left amygdala, left insula, left } \\
\text { nucleus accumbens }\end{array}$ & 1490 & 4.55 & -61 & -1 & 2 \\
\hline Left middle and superior frontal gyri & 188 & 3.22 & -25 & 29 & 47 \\
\hline Cerebellum & 149 & 3.05 & -34 & -79 & -22 \\
\hline $\begin{array}{l}\text { Group } \times \text { task condition: } \mathrm{Pl}>\text { comparisons } \times \\
\quad \mathrm{CS}+>\mathrm{CS}-\end{array}$ & & & & & \\
\hline $\begin{array}{l}\text { Right hippocampus, right parahippocampal } \\
\text { cortex }\end{array}$ & 41 & 3.24 & 23 & -34 & 10 \\
\hline Cuneus & 32 & 3.59 & 8 & -73 & 23 \\
\hline $\begin{array}{l}\text { Age } \times \text { task condition: age predicts decreased } \\
\text { activation for } \mathrm{CS}+>\mathrm{CS}-\end{array}$ & & & & & \\
\hline $\begin{array}{l}\text { Left lateral orbitofrontal cortex } \\
\text { Group } \times \text { task condition } \times \text { age: age predicts } \\
\text { decreased activation for comparisons, } \\
\text { more activation for PIs for } \mathrm{CS}+>\mathrm{CS}-\end{array}$ & 172 & 3.06 & -43 & -61 & -25 \\
\hline Cerebellum & 172 & 3.06 & -43 & -61 & -25 \\
\hline Midbrain & 46 & 2.96 & 2 & -10 & -19 \\
\hline Cerebellum & 35 & 3.47 & 29 & -52 & -34 \\
\hline Precuneus & 30 & 3.84 & 29 & -58 & 32 \\
\hline
\end{tabular}

assessment of the more orbital vlPFC cluster identified revealed that connectivity was not significantly different from zero for any condition in any group aside from CS - trials for PI youth $(p>$ $0.08)$, where connectivity was significantly negative $\left(t_{(45)}=2.59\right.$, $p<0.05)$. Connectivity was not significantly different from zero for any condition in any group in the second vlPFC cluster localized in the inferior frontal gyrus $(p>0.25)$.

Hippocampal connectivity. A whole-brain, generalized PPI analysis was performed using the hippocampus cluster identified by the condition $(\mathrm{CS}+>\mathrm{CS}-) \times$ group interaction term as a seed region. Across both groups, connectivity between the hippocampus and vmPFC, ventral striatum, and posterior insula differed significantly as a function of task condition (Table 4). Connectivity was significantly positive for CS + trials, and significantly negative for $\mathrm{CS}-$ trials in vmPFC and the ventral striatum. Connectivity in the posterior insula was negative for both $\mathrm{CS}+$ and $\mathrm{CS}-$ trials, but was more strongly negative for CS - trials.

Hippocampal connectivity in vmPFC, dmPFC, left middle frontal gyrus (MFG), posterior cingulate cortex (PCC), thalamus, and precuneus varied according to the group $\times$ condition interaction (Table 4). As shown in Figure 3, the vmPFC cluster identified by the group $\times$ condition interaction overlapped with the vmPFC cluster identified by the main effect of condition, suggesting that PI youth were driving the main effect. Interactive effects were primarily driven by PI youth trending toward negative connectivity with the hippocampus on CS - trials and positive connectivity on CS + trials, and by comparison youth showing the opposite pattern. One-sample $t$ tests revealed that

\section{A Hippocampal activation in PI group only}
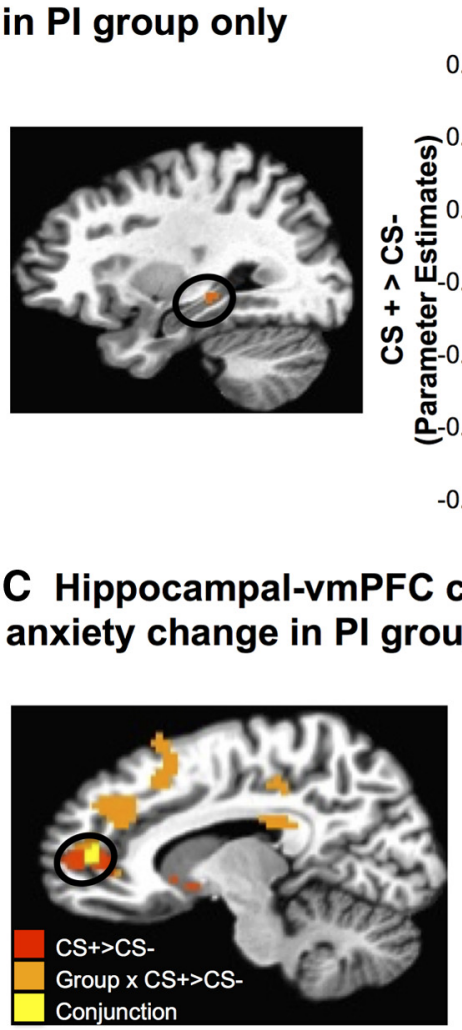
anxiety change in $\mathrm{PI}$ group

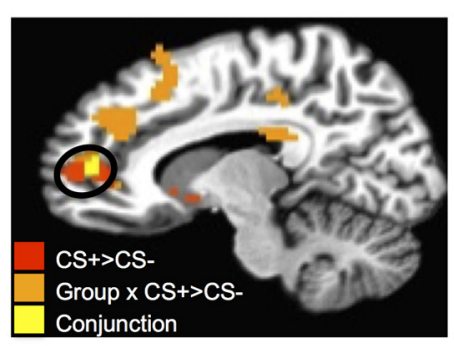

\section{B Learning predicts current anxiety in PI group}

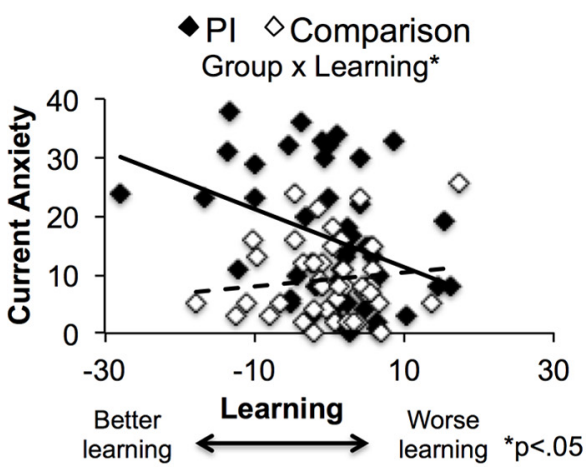

\section{Hippocampal-vmPFC connectivity predicts}

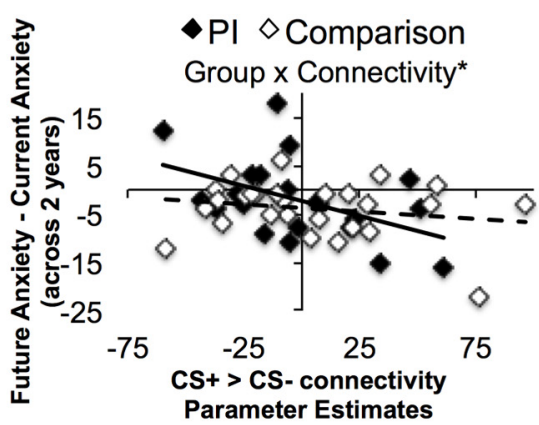

Figure 3. Hippocampal activation and connectivity. $\boldsymbol{A}$, Pl youth recruited the hippocampus more strongly for $C S+$ trials than for $C S-$ trials relative to comparisons, $p<0.05$ FWE corrected. $\boldsymbol{B}$, Learning (adjusted for age and sex) correlated with current anxiety for Pl youth. C, Hippocampal-vmPFC connectivity was identified by the main effect of condition (CS $+>C S-;$ shown in red) and by the condition $X$ for PI youth group interaction condition (shown in orange). Overlap between the two analyses is shown in yellow. Hippocampal-vmPFC connectivity in the vmPFC cluster identified by the main effect of condition (adjusted for age, sex, and baseline anxiety) predicted a significant decrease in anxiety symptoms 2 years later. All error bars reflect between-subjects $S E$. 
Table 3. Brain regions showing differential amygdala connectivity during aversive learning

\begin{tabular}{|c|c|c|c|c|c|}
\hline \multirow[b]{2}{*}{ Region } & \multirow{2}{*}{$\begin{array}{l}\text { Voxels } \\
(n)\end{array}$} & \multirow[b]{2}{*}{$t$} & \multicolumn{3}{|c|}{$\begin{array}{l}\text { Talairach } \\
\text { coordinates }\end{array}$} \\
\hline & & & $x$ & $y$ & $z$ \\
\hline \multirow{2}{*}{\multicolumn{6}{|c|}{$\begin{array}{l}\text { Main effect of task condition: } \mathrm{CS}+>\mathrm{CS}- \\
\text { Right superior frontal gyrus } \\
\text { Group } \times \text { task condition: } \mathrm{PI}>\text { comparisons } \times \\
\quad \mathrm{CS}+>\mathrm{CS}-\end{array}$}} \\
\hline & & & & & \\
\hline $\mathrm{dmPFC}$ & 246 & 3.03 & -4 & 65 & 20 \\
\hline vmPFC & 52 & 3.66 & -4 & 59 & -7 \\
\hline Left posterior lateral OFC & 42 & 3.23 & -37 & 32 & -19 \\
\hline Left inferior frontal gyrus & 40 & 3.09 & -52 & 35 & -1 \\
\hline \multicolumn{5}{|l|}{ Age $\times$ task condition $^{a}$} & \\
\hline
\end{tabular}

${ }^{a}$ No regions identified.

among PI youth connectivity was significantly more negative than zero for CS - trials in $\operatorname{dmPFC}\left(t_{(45)}=2.20, p<0.05\right)$ and the thalamus $\left(t_{(45)}=3.21, p<0.005\right)$, and was significantly more positive than zero for CS + trials in $\operatorname{vmPFC}\left(t_{(45)}=1.99, p \leq\right.$ $0.05)$, PCC $\left(t_{(45)}=2.50, p<0.05\right)$, and precuneus $\left(t_{(45)}=2.54\right.$, $p<0.05)$. All other conditions were not significantly different from zero for PI youth ( $p>0.08$ ). Within the comparison group, one-sample $t$ tests revealed that connectivity was significantly more positive than zero for CS - trials in the precuneus $\left(t_{(42)}=\right.$ $2.19, p<0.05)$, whereas connectivity was significantly more negative than zero for CS + trials in $\operatorname{dmPFC}\left(t_{(42)}=2.13, p<0.05\right)$, left MFG $\left(t_{(42)}=2.08, p<0.05\right)$, and thalamus $\left(t_{(42)}=3.14, p<\right.$ $0.005)$. All other conditions were not significantly different from zero for comparison youth $(p>0.07)$.

Neural predictors of anxiety

It was hypothesized that PI youth who demonstrated stronger connectivity within amygdala-hippocampal-prefrontal regions during aversive learning would have reduced anxiety relative to other PI youth. Comparison youth were examined as well to

Table 4. Brain regions showing differential hippocampal connectivity during aversive learning

\begin{tabular}{|c|c|c|c|c|c|}
\hline \multirow[b]{2}{*}{ Region } & \multirow{2}{*}{$\begin{array}{l}\text { Voxels } \\
(n)\end{array}$} & \multirow[b]{2}{*}{$t$} & \multicolumn{3}{|c|}{$\begin{array}{l}\text { Talairach } \\
\text { coordinates }\end{array}$} \\
\hline & & & $x$ & $y$ & $z$ \\
\hline \multicolumn{6}{|l|}{ Main effect of task condition: $\mathrm{CS}+>\mathrm{CS}-$} \\
\hline $\begin{array}{l}\text { vmPFC } \\
\text { Ventral striatum }\end{array}$ & 82 & 3.25 & -1 & 35 & \\
\hline Ventral striatum & 56 & 2.96 & -1 & 5 & -7 \\
\hline Posterior insula & 39 & 3.91 & 44 & -16 & 11 \\
\hline \multicolumn{4}{|c|}{ Group $\times$ task condition: $\mathrm{PI}>$ comparisons $\times$} & \multicolumn{2}{|c|}{$\mathrm{CS}+>\mathrm{CS}-$} \\
\hline Right superior frontal gyrus, dmPFC & 483 & 4.46 & 20 & 17 & 62 \\
\hline Left middle frontal gyrus & 87 & 3.78 & -25 & 23 & 56 \\
\hline Corpus callosum, thalamus & 75 & 3.20 & 2 & -16 & 20 \\
\hline Posterior cingulate cortex & 60 & 3.79 & 2 & -28 & 44 \\
\hline vmPFC & 44 & 3.04 & 2 & 53 & 5 \\
\hline Precuneus & 44 & 3.75 & -1 & -73 & 41 \\
\hline \multicolumn{6}{|c|}{$\begin{array}{l}\text { Age } \times \text { task condition: age predicts decreased } \\
\text { connectivity for } \mathrm{CS}+>\mathrm{CS}-\end{array}$} \\
\hline vmPFC & 83 & 3.62 & -1 & 50 & -4 \\
\hline \multicolumn{6}{|c|}{$\begin{array}{l}\text { Age } \times \text { task condition: age predicts increased } \\
\text { connectivity for } C S+>C S \times\end{array}$} \\
\hline Precentral gyrus & 58 & 3.32 & 2 & 5 & 68 \\
\hline Central sulcus & 52 & 3.19 & -4 & -13 & 71 \\
\hline Cerebellum & 49 & 3.85 & 26 & -37 & -49 \\
\hline Group $\times$ task condition $\times$ age $^{a}$ & & & & & \\
\hline
\end{tabular}

${ }^{a}$ No regions identified. establish whether effects were specific to PI youth. Within the prefrontal cortex, analyses were focused on the vmPFC because it has been tightly tied to extinction, reduced anxiety, and fear regulation (Etkin et al., 2011). As such, we examined whether amygdala-vmPFC connectivity and hippocampal-vmPFC connectivity predicted (1) current anxiety and (2) changes in anxiety from the time of scanning to 2 years later.

Anxiety symptomology and amygdala functional connectivity. As reported above, no connectivity was observed between the amygdala and vmPFC in the main effect of condition $(\mathrm{CS}+>$ $\mathrm{CS}-$ ) contrast. However, the condition $\times$ group interaction term revealed significant connectivity between the amygdala and vmPFC. $\beta$ Values were extracted from this cluster, and the resulting contrast value (i.e., each participant's $\beta$ value for $\mathrm{CS}+>\mathrm{CS}-$ trials) was used as a predictor in two univariate GLM analyses.

Baseline anxiety symptomology and amygdala functional connectivity. In the first analysis, the amygdala-vmPFC connectivity contrast value was entered along with group, mean-centered age, sex, and the interaction term between the amygdala-vmPFC connectivity contrast value and group were entered as predictors, and current anxiety was entered as the dependent variable. As reported in prior analyses, PI youth exhibited higher current anxiety symptomology than comparison youth $\left(F_{(1,82)}=12.17, p=0.001\right)$, but no other predictors were significantly associated with current anxiety $(p>0.07)$.

Future change in anxiety symptomology and amygdala functional connectivity. In the second analysis, the amygdalavmPFC connectivity contrast value was entered along with group, mean-centered age, sex, the interaction term between the amygdala-vmPFC connectivity contrast value and group, baseline anxiety (mean-centered), and the interaction term between baseline anxiety and group were entered as predictors, and change in anxiety was entered as the dependent variable. As reported previously, comparison youth experienced steeper declines in anxiety symptomology over time than PI youth $\left(F_{(1,40)}=4.00, p=0.05\right)$, and individuals with higher baseline anxiety experienced greater decreases in anxiety symptomology over time $\left(F_{(1,40)}=9.23, p<0.005\right)$. No other predictors, including amygdala-vmPFC connectivity and the interaction term between group and amygdala-vmPFC connectivity, were associated with changes in anxiety over time $(p>0.15)$.

Anxiety symptomology and hippocampal functional connectivity. As described in the functional connectivity analysis above, significant hippocampal-vmPFC connectivity was revealed by both the main effect of condition contrast $(\mathrm{CS}+>\mathrm{CS}-$ ) and the interaction term between group and condition. Hippocampal connectivity analyses examining anxiety were conducted using the vmPFC cluster identified by the main effect of condition because both PI and comparison participants showed connectivity in this region. Beta values were extracted from this vmPFC cluster, and the resulting $\mathrm{CS}+>\mathrm{CS}-$ contrast value was entered into two univariate GLM analyses.

Baseline anxiety symptomology and hippocampal functional connectivity. In the first analysis, the hippocampal-vmPFC connectivity contrast value was entered along with group, mean-centered age, sex, and the interaction term between the hippocampal-vmPFC connectivity and group as predictors, and current anxiety was entered as the dependent variable. There was no effect of hippocampal-vmPFC connectivity on current anxiety scores, but PI youth exhibited higher anxiety symptomology than comparison youth $\left(F_{(1,82)}=9.24, p<0.005\right)$ and females exhibited greater current anxiety than males $\left(F_{(1,82)}=4.24, p<\right.$ 


\section{$\mathrm{PI}=$ Comparison $\quad \mathrm{PI}>$ Comparison}

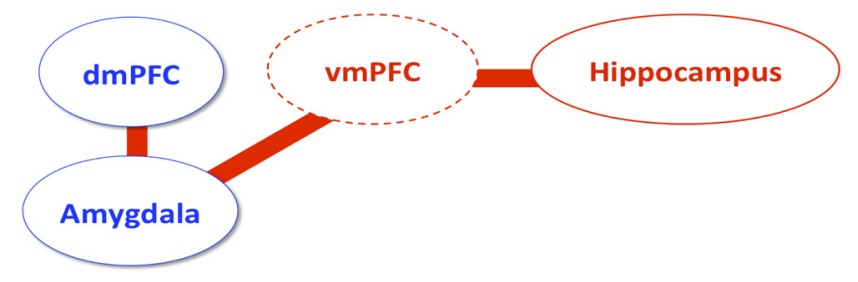

Figure 4. Schematic of brain regions engaged during aversive learning in comparison and PI youth (circles, activation; lines, connectivity). Blue colors indicate comparable activation or connectivity for $\mathrm{Pl}$ and comparison youth. Red colors indicate that the $\mathrm{CS}+>\mathrm{CS}-$ contrast of activation or connectivity was greater for $\mathrm{PI}$ youth than for comparison youth. The dotted line around vmPFC indicates that vMPFC was identified in connectivity but not activation analyses.

$0.05)$. No other predictors were significantly associated with current anxiety $(p>0.31)$.

Future change in anxiety symptomology and hippocampal functional connectivity. In the second analysis, hippocampal-vmPFC connectivity was entered as a predictor along with group, meancentered age, sex, the hippocampal-vmPFC connectivity $\times$ group interaction term, baseline anxiety (mean-centered), and the group $\times$ baseline anxiety interaction term. Change in anxiety was entered as the dependent variable. Significant main effects of group $\left(F_{(1,40)}=7.13, p<0.05\right.$; the comparison group showed steeper declines in anxiety over time than the PI group), baseline anxiety $\left(F_{(1,40)}=10.97, p<0.005\right.$; higher baseline anxiety predicted steeper declines in anxiety over time), and hippocampalvmPFC connectivity were observed $\left(F_{(1,40)}=8.30, p<0.01\right.$; greater connectivity predicted steeper declines in anxiety over time). Importantly, hippocampal-vmPFC connectivity interacted with PI group to predict anxiety change $\left(F_{(1,40)}=4.14, p<\right.$ $0.05)$. Follow-up correlational analyses conducted within each group revealed that connectivity predicted reduced anxiety over time within the PI group $(r=-0.53, p=0.01)$ but not the comparison group $(r=-0.18, p=0.38)$. There were no other main effects or interactions $(p>0.15)$.

\section{Discussion}

The present study examined the associations among prior institutionalization, a highly adverse caregiving experience, and the neural bases of aversive learning during childhood and adolescence. While prior work has examined aversive learning in adults who experienced early adversity (Bremner et al., 2005), the present study highlights the importance of examining these processes during development. Consistent with prior work showing that children with high anxiety, but not those with low anxiety, show effective CS + versus CS - discrimination learning (Jovanovic et al., 2014), we observed that anxiety within the PI group was associated with behavioral evidence of learning. PI and comparison youth were equally capable of behavioral discrimination and showed comparable amygdala activation during aversive learning (Fig. 4). However, PI youth additionally recruited the hippocampus and exhibited significant amygdala-prefrontal connectivity and hippocampal-prefrontal connectivity during aversive learning, more closely resembling results observed in adult samples (Sehlmeyer et al., 2009). Hippocampal-prefrontal connectivity predicted a prospective reduction in anxiety 2 years later for the PI group. These results suggest that age-atypical hippocampal-vmPFC connectivity may be an important source of resilience for youth with a history of caregiving adversity.
The present results show that aversive learning relies upon a more distributed neural circuit in PI youth than in comparison youth, which includes not only the amygdala, but also the prefrontal cortex and the hippocampus, thereby approximating adult patterns of activity (Sehlmeyer et al., 2009). The hippocampus is critical for binding information during memory encoding (Squire et al., 2004) and regulating fear and stress responses (Jacobson and Sapolsky, 1991; Goosens, 2011; Frodl and O'Keane, 2013). In adults, the hippocampus works in concert with the amygdala and PFC to contextualize cues during aversive learning, facilitate escape behavior from aversive stimuli, and attenuate fear expression during extinction (Sotres-Bayon and Quirk, 2010; Sotres-Bayon et al., 2012). The fact that hippocampalvmPFC connectivity differed for CS + and CS - trials for PI versus comparison youth suggests that this circuitry plays an important role for identifying contextual boundary conditions during aversive learning. Rodent models suggest that parental deprivation can lead to precocious hippocampal development (Roceri et al., 2004; Huang et al., 2005) and more enduring fear memories during development (Callaghan and Richardson, 2011). Together with the present findings, this suggests that early caregiving adversity changes the pacing of amygdala-hippocampus-vmPFC circuit development and, in doing so, alters the way that aversive learning is represented in the brain.

Prior research has linked hippocampal recruitment with perceived controllability over aversive situations (Shors et al., 1989) and to contingency learning (Knight et al., 2009). Together with the present findings, this suggests that adversity-induced alterations in hippocampal function may facilitate adaptive learning, at least in the short term, about threats in one's environment. However, this conclusion should be considered with two caveats. First, it is important to consider why better discrimination learning was associated with greater current anxiety (though not future anxiety) among PI youth and why other developmental work has linked anxiety with better discrimination learning (Jovanovic et al., 2014), whereas in adult samples better discrimination learning is often associated with less anxiety (Lissek et al., 2005). This paradox fits within a broader literature suggesting that stress and associated anxiety may accelerate and enhance aversive-learning processes during development but may exert opposite effects in adulthood. For example, rodent work has suggested that parental deprivation can lead to enhanced hippocampal function during development, and reduced function in adulthood (Roceri et al., 2004). At present, it is unknown whether PI individuals in adulthood would show more or less hippocampal recruitment than comparison adults during aversive learning. Such questions underscore the need for longitudinal studies of aversive learning in PI individuals. Second, it is unclear whether early adversity induces greater hippocampal recruitment during learning in general or during aversive learning specifically. In adult animals, early parental deprivation has been linked to diminished hippocampal function and poor performance on cognitive tasks (Hulshof et al., 2011), but also to enhanced hippocampally mediated performance under stressful conditions in adulthood (Oomen et al., 2010). As such, future human work ought to examine the effects of early caregiving adversity on hippocampal function across different learning tasks.

Although group differences were observed, the present results provide compelling evidence for moving beyond group averages, and capitalizing on individual differences to identify sources of risk and resilience. Specifically, individual differences in hippocampal-vmPFC connectivity during aversive learning predict anxiety outcomes among individuals who have experienced early 
caregiving adversity. Across species, interactions between vmPFC and the amygdala and hippocampus support threat avoidance and escape (Amat et al., 2005; Kerr et al., 2012; Collins et al., 2014), as well as fear extinction and reversal (Morgan et al., 1993; Milad et al., 2007; Schiller et al., 2008). Specifically, hippocampal-prefrontal dynamics are critical for learning and updating contextual information and boundary conditions relating to threat (Preston and Eichenbaum, 2013; Korzus, 2015; Besnard and Sahay, 2016). Neuroimaging data have consistently linked vmPFC activation to lower anxiety in healthy individuals (Wager et al., 2009; Somerville et al., 2013), and hypoactive vmPFC recruitment to anxiety disorders such as post-traumatic stress disorder (Etkin and Wager, 2007), suggesting that vmPFC is critical for regulating fear and anxiety. Thus, hippocampal-vmPFC connectivity may help regulate threat discrimination in youth exposed to early adversity.

In nonhuman animals, caregiving adversity accelerates the ontogenetic development of aversive-learning and extinction processes supported by interactions among the vmPFC, amygdala, and hippocampus (Callaghan and Richardson, 2011, 2012). While institutional rearing significantly increases the risk of internalizing symptoms during childhood (Humphreys et al., 2015), PI youth who show more adult-like vmPFC-amygdala functional connectivity exhibit less separation anxiety during childhood and adolescence (Gee et al., 2013). This suggests that some, but not all, individuals who experience early caregiving adversity adapt by acquiring a more adult-like neural phenotype that has anxiolytic benefits. The present results build on this prior work by showing that hippocampal-vmPFC connectivity during aversive learning predicts less anxiety over a 2 year period. These results suggest that greater prefrontal-hippocampal communication during development may protect against a pathological course of anxiety for individuals who have experienced caregiving adversity.

The present results ought to be considered alongside the limitations of this study. First, for ethical reasons, participants were not randomly assigned to have received institutional care or not in early childhood. As such, PI and comparison youth could have differed because of some variable other than their early life experiences. This seems unlikely, however, given that random assignment of care in other studies strongly suggests that the effects of institutionalization are causal (Zeanah et al., 2009). Second, the present study examined aversive learning and escape learning simultaneously, making it somewhat difficult to tease apart these two processes. However, this paradigm has the distinct advantage of providing a behavioral index of learning that cannot be inferred from brain data alone, and that is also more specific and resistant to artifacts than measures such as skin conductance. Third, it is unknown whether the present findings observed in PI youth would generalize to youth who have experienced other forms of adversity (e.g., abuse and poverty; Jovanovic et al., 2014). An advantage to the present sample is that since all PI youth in this study left institutional care at a young age, it is highly likely that the observed effects are due to early adverse experiences alone rather than to sustained and current adversity. Finally, while conducting research with a large sample with a relatively wide age range provides many benefits, including enhanced statistical power, it also poses challenges. However, within this age range in this sample, there were no apparent agerelated effects in the targeted analyses performed.

The present study revealed that PI and comparison youth are capable of amygdala-based aversive learning. However, aversive learning following institutionalization was associated with a broader recruitment of prefrontal and subcortical circuitry. Beyond establishing these basic differences between PI and comparison youth, the present study identified a neural adaptation among PI youth that predicted greater resilience over time. Specifically, stronger hippocampal-prefrontal coupling prospectively predicted a reduction in anxiety symptomology over a 2 year period. This suggests that greater integration of information across brain systems involved in aversive learning and regulation is a protective factor for individuals who have experienced adversity. This finding has significant implications for understanding how neural adaptations to early adversity at one point in development may prospectively buffer individuals against future anxiety.

\section{References}

Amat J, Baratta MV, Paul E, Bland ST, Watkins LR, Maier SF (2005) Medial prefrontal cortex determines how stressor controllability affects behavior and dorsal raphe nucleus. Nat Neurosci 8:365-371. CrossRef Medline

Bagot RC, van Hasselt FN, Champagne DL, Meaney MJ, Krugers HJ, Joëls M (2009) Maternal care determines rapid effects of stress mediators on synaptic plasticity in adult rat hippocampal dentate gyrus. Neurobiol Learn Mem 92:292-300. CrossRef Medline

Besnard A, Sahay A (2016) Adult hippocampal neurogenesis, fear generalization, and stress. Neuropsychopharmacology 41:24-44. CrossRef Medline

Birmaher B, Brent DA, Chiappetta L, Bridge J, Monga S, Baugher M (1999) Psychometric properties of the Screen for Child Anxiety Related Emotional Disorders (SCARED): a replication study. J Am Acad Child Adolesc Psychiatry 38:1230-1236. CrossRef Medline

Blaise JH, Koranda JL, Chow U, Haines KE, Dorward EC (2008) Neonatal isolation stress alters bidirectional long-term synaptic plasticity in amygdalo-hippocampal synapses in freely behaving adult rats. Brain Res 1193:25-33. CrossRef Medline

Bremner JD, Vermetten E, Schmahl C, Vaccarino V, Vythilingam M, Afzal N, Grillon C, Charney DS (2005) Positron emission tomographic imaging of neural correlates of a fear acquisition and extinction paradigm in women with childhood sexual-abuse-related post-traumatic stress disorder. Psychol Med 35:791-806. CrossRef Medline

Britton JC, Grillon C, Lissek S, Norcross MA, Szuhany KL, Chen G, Ernst M, Nelson EE, Leibenluft E, Shechner T, Pine DS (2013) Response to learned threat: an FMRI study in adolescent and adult anxiety. Am J Psychiatry 170:1195-1204. CrossRef Medline

Cain CK, LeDoux JE (2007) Escape from fear: a detailed behavioral analysis of two atypical responses reinforced by CS termination. J Exp Psychol Anim Behav Process 33:451-463. CrossRef Medline

Callaghan BL, Richardson R (2011) Maternal separation results in early emergence of adult-like fear and extinction learning in infant rats. Behav Neurosci 125:20-28. CrossRef Medline

Callaghan BL, Richardson R (2012) Early-life stress affects extinction during critical periods of development: an analysis of the effects of maternal separation on extinction in adolescent rats. Stress 15:671-679. CrossRef Medline

Callaghan BL, Sullivan RM, Howell B, Tottenham N (2014) The international society for developmental psychobiology Sackler symposium: early adversity and the maturation of emotion circuits - a cross-species analysis. Dev Psychobiol 56:1635-1650. CrossRef Medline

Cohen Kadosh K, Haddad AD, Heathcote LC, Murphy RA, Pine DS, Lau JY (2015) High trait anxiety during adolescence interferes with discriminatory context learning. Neurobiol Learn Mem 123:50-57. CrossRef Medline

Collins KA, Mendelsohn A, Cain CK, Schiller D (2014) Taking action in the face of threat: neural synchronization predicts adaptive coping. J Neurosci 34:14733-14738. CrossRef Medline

Corcoran KA, Quirk GJ (2007) Activity in prelimbic cortex is necessary for the expression of learned, but not innate, fears. J Neurosci 27:840-844. CrossRef Medline

Cox RW (1996) AFNI: software for analysis and visualization of functional magnetic resonance neuroimages. Comput Biomed Res 29:162-173. CrossRef Medline

Eickhoff SB, Stephan KE, Mohlberg H, Grefkes C, Fink GR, Amunts K, Zilles K (2005) A new SPM toolbox for combining probabilistic cytoarchitectonic maps and functional imaging data. Neuroimage 25:1325-1335. CrossRef Medline 
Etkin A, Wager TD (2007) Functional neuroimaging of anxiety: a metaanalysis of emotional processing in PTSD, social anxiety disorder, and specific phobia. Am J Psychiatry 164:1476-1488. CrossRef Medline

Etkin A, Egner T, Kalisch R (2011) Emotional processing in anterior cingulate and medial prefrontal cortex. Trends Cogn Sci 15:85-93. CrossRef Medline

Friston KJ, Buechel C, Fink GR, Morris J, Rolls E, Dolan RJ (1997) Psychophysiological and modulatory interactions in neuroimaging. Neuroimage 6:218-229. CrossRef Medline

Frodl T, O'Keane V (2013) How does the brain deal with cumulative stress? A review with focus on developmental stress, HPA axis function and hippocampal structure in humans. Neurobiol Dis 52:24-37. CrossRef Medline

Fullana MA, Harrison BJ, Soriano-Mas C, Vervliet B, Cardoner N, Àvila Parcet A, Radua J (2016) Neural signatures of human fear conditioning: an updated and extended meta-analysis of fMRI studies. Mol Psychiatry 21:500-508. CrossRef Medline

Gee DG, Gabard-Durnam LJ, Flannery J, Goff B, Humphreys KL, Telzer EH, Hare TA, Bookheimer SY, Tottenham N (2013) Early developmental emergence of human amygdala-prefrontal connectivity after maternal deprivation. Proc Natl Acad Sci U S A 110:15638-15643. CrossRef Medline

Goosens KA (2011) Hippocampal regulation of aversive memories. Curr Opin Neurobiol 21:460-466. CrossRef Medline

Gorka AX, Hanson JL, Radtke SR, Hariri AR (2014) Reduced hippocampal and medial prefrontal gray matter mediate the association between reported childhood maltreatment and trait anxiety in adulthood and predict sensitivity to future life stress. Biol Mood Anxiety Disord 4:12. CrossRef Medline

Greco JA, Liberzon I (2016) Neuroimaging of fear-associated learning. Neuropsychopharmacology 41:320-334. CrossRef Medline

Huang CC, Chou PH, Yang CH, Hsu KS (2005) Neonatal isolation accelerates the developmental switch in the signalling cascades for long-term potentiation induction. J Physiol 569:789-799. CrossRef Medline

Hulshof HJ, Novati A, Sgoifo A, Luiten PG, den Boer JA, Meerlo P (2011) Maternal separation decreases adult hippocampal cell proliferation and impairs cognitive performance but has little effect on stress sensitivity and anxiety in adult Wistar rats. Behav Brain Res 216:552-560. CrossRef Medline

Humphreys KL, Gleason MM, Drury SS, Miron D, Nelson CA 3rd, Fox NA, Zeanah CH (2015) Effects of institutional rearing and foster care on psychopathology at age 12 years in Romania: follow-up of an open, randomised controlled trial. Lancet Psychiatry 2:625-634. CrossRef Medline

Indovina I, Robbins TW, Núñez-Elizalde AO, Dunn BD, Bishop SJ (2011) Fear-conditioning mechanisms associated with trait vulnerability to anxiety in humans. Neuron 69:563-571. CrossRef Medline

Jackowski A, Perera TD, Abdallah CG, Garrido G, Tang CY, Martinez J, Mathew SJ, Gorman JM, Rosenblum LA, Smith EL, Dwork AJ, Shungu DC, Kaffman A, Gelernter J, Coplan JD, Kaufman J (2011) Early-life stress, corpus callosum development, hippocampal volumetrics, and anxious behavior in male nonhuman primates. Psychiatry Res 192:37-44. CrossRef Medline

Jacobson L, Sapolsky R (1991) The role of the hippocampus in feedback regulation of the hypothalamic-pituitary-adrenocortical axis. Endocr Rev 12:118-134. CrossRef Medline

Jovanovic T, Nylocks KM, Gamwell KL, Smith A, Davis TA, Norrholm SD, Bradley B (2014) Development of fear acquisition and extinction in children: effects of age and anxiety. Neurobiol Learn Mem 113:135-142. CrossRef Medline

Kerr DL, McLaren DG, Mathy RM, Nitschke JB (2012) Controllability modulates the anticipatory response in the human ventromedial prefrontal cortex. Front Psychol 3:557. CrossRef Medline

Kessler RC, McLaughlin KA, Green JG, Gruber MJ, Sampson NA, Zaslavsky AM, Aguilar-Gaxiola S, Alhamzawi AO, Alonso J, Angermeyer M, Benjet C, Bromet E, Chatterji S, de Girolamo G, Demyttenaere K, Fayyad J, Florescu S, Gal G, Gureje O, Haro JM, et al. (2010) Childhood adversities and adult psychopathology in the WHO World Mental Health Surveys. Br J Psychiatry 197:378-385. CrossRef Medline

Kheirbek MA, Klemenhagen KC, Sahay A, Hen R (2012) Neurogenesis and generalization: a new approach to stratify and treat anxiety disorders. Nat Neurosci 15:1613-1620. CrossRef Medline

Kim JH, Li S, Hamlin AS, McNally GP, Richardson R (2012) Phosphoryla- tion of mitogen-activated protein kinase in the medial prefrontal cortex and the amygdala following memory retrieval or forgetting in developing rats. Neurobiol Learn Mem 97:59-68. CrossRef Medline

Knight DC, Wood KH (2011) Investigating the neural mechanisms of aware and unaware fear memory with fMRI. J Vis Exp (56):e3083. CrossRef Medline

Knight DC, Waters NS, Bandettini PA (2009) Neural substrates of explicit and implicit fear memory. Neuroimage 45:208-214. CrossRef Medline

Korzus E (2015) Prefrontal cortex in learning to overcome generalized fear. J Exp Neurosci 9:53-56. CrossRef Medline

LeDoux JE, Cicchetti P, Xagoraris A, Romanski LM (1990) The lateral amygdaloid nucleus: sensory interface of the amygdala in fear conditioning. J Neurosci 10:1062-1069. Medline

Li S, Kim JH, Richardson R (2012) Differential involvement of the medial prefrontal cortex in the expression of learned fear across development. Behav Neurosci 126:217-225. CrossRef Medline

Lissek S, Powers AS, McClure EB, Phelps EA, Woldehawariat G, Grillon C, Pine DS (2005) Classical fear conditioning in the anxiety disorders: a meta-analysis. Behav Res Ther 43:1391-1424. CrossRef Medline

Luby J, Belden A, Botteron K, Marrus N, Harms MP, Babb C, Nishino T, Barch D (2013) The effects of poverty on childhood brain development: the mediating effect of caregiving and stressful life events. JAMA Pediatr 167:1135-1142. CrossRef Medline

Malter Cohen M, Jing D, Yang RR, Tottenham N, Lee FS, Casey BJ (2013) Early-life stress has persistent effects on amygdala function and development in mice and humans. Proc Natl Acad Sci U S A 110:18274-18278. CrossRef Medline

Maren S, Phan KL, Liberzon I (2013) The contextual brain: implications for fear conditioning, extinction and psychopathology. Nat Rev Neurosci 14:417-428. CrossRef Medline

McAllister WR, McAllister DE (1962) Postconditioning delay and intensity of shock as factors in the measurement of acquired fear. J Exp Psychol 64:110-116. CrossRef

McEwen BS, Nasca C, Gray JD (2016) Stress effects on neuronal structure: hippocampus, amygdala, and prefrontal cortex. Neuropsychopharmacology 41:3-23. CrossRef Medline

Mehta MA, Golembo NI, Nosarti C, Colvert E, Mota A, Williams SC, Rutter M, Sonuga-Barke EJ (2009) Amygdala, hippocampal and corpus callosum size following severe early institutional deprivation: the English and Romanian Adoptees study pilot. J Child Psychol Psychiatry 50:943-951. CrossRef Medline

Milad MR, Wright CI, Orr SP, Pitman RK, Quirk GJ, Rauch SL (2007) Recall of fear extinction in humans activates the ventromedial prefrontal cortex and hippocampus in concert. Biol Psychiatry 62:446-454. CrossRef Medline

Mineka S, Oehlberg K (2008) The relevance of recent developments in classical conditioning to understanding the etiology and maintenance of anxiety disorders. Acta Psychol 127:567-580. CrossRef

Mirescu C, Peters JD, Gould E (2004) Early life experience alters response of adult neurogenesis to stress. Nat Neurosci 7:841-846. CrossRef Medline

Mobbs D, Hagan CC, Dalgleish T, Silston B, Prévost C (2015) The ecology of human fear: survival optimization and the nervous system. Front Neurosci 9:55. CrossRef Medline

Morgan MA, Romanski LM, LeDoux JE (1993) Extinction of emotional learning: contribution of medial prefrontal cortex. Neurosci Lett 163: 109-113. CrossRef Medline

Moriceau S, Sullivan RM (2006) Maternal presence serves as a switch between learning fear and attraction in infancy. Nat Neurosci 9:1004-1006. CrossRef Medline

Mowrer OH, Lamoreaux RR (1946) Fear as an intervening variable in avoidance conditioning. J Comp Psychol 39:29-50. CrossRef Medline

Muhammad A, Carroll C, Kolb B (2012) Stress during development alters dendritic morphology in the nucleus accumbens and prefrontal cortex. Neuroscience 216:103-109. CrossRef Medline

Neumann DL, Waters AM, Westbury HR, Henry J (2008) The use of an unpleasant sound unconditional stimulus in an aversive conditioning procedure with 8- to 11-year-old children. Biol Psychol 79:337-342. CrossRef Medline

Ono M, Kikusui T, Sasaki N, Ichikawa M, Mori Y, Murakami-Murofushi K (2008) Early weaning induces anxiety and precocious myelination in the anterior part of the basolateral amygdala of male BALB/c mice. Neuroscience 156:1103-1110. CrossRef Medline 
Oomen CA, Soeters H, Audureau N, Vermunt L, van Hasselt FN, Manders EM, Joëls M, Lucassen PJ, Krugers H (2010) Severe early life stress hampers spatial learning and neurogenesis, but improves hippocampal synaptic plasticity and emotional learning under high-stress conditions in adulthood. J Neurosci 30:6635-6645. CrossRef Medline

Pagliaccio D, Luby JL, Bogdan R, Agrawal A, Gaffrey MS, Belden AC, Botteron KN, Harms MP, Barch DM (2014) Stress-system genes and life stress predict cortisol levels and amygdala and hippocampal volumes in children. Neuropsychopharmacology 39:1245-1253. CrossRef Medline

Pattwell SS, Bath KG, Casey BJ, Ninan I, Lee FS (2011) Selective earlyacquired fear memories undergo temporary suppression during adolescence. Proc Natl Acad Sci U S A 108:1182-1187. CrossRef Medline

Pattwell SS, Duhoux S, Hartley CA, Johnson DC, Jing D, Elliott MD, Ruberry EJ, Powers A, Mehta N, Yang RR, Soliman F, Glatt CE, Casey BJ, Ninan I, Lee FS (2012) Altered fear learning across development in both mouse and human. Proc Natl Acad Sci U S A 109:16318-16323. CrossRef Medline

Penney RK, Kirwin PM (1965) Differential adaptation of anxious and nonanxious children in instrumental escape conditioning. J Exp Psychol 70: 539-541. CrossRef Medline

Preston AR, Eichenbaum H (2013) Interplay of hippocampus and prefrontal cortex in memory. Curr Biol 23:R764-R773. CrossRef Medline

Reichenberg A, Caspi A, Harrington H, Houts R, Keefe RS, Murray RM, Poulton R, Moffitt TE (2010) Static and dynamic cognitive deficits in childhood preceding adult schizophrenia: a 30-year study. Am J Psychiatry 167:160-169. CrossRef Medline

Roceri M, Cirulli F, Pessina C, Peretto P, Racagni G, Riva MA (2004) Postnatal repeated maternal deprivation produces age-dependent changes of brain-derived neurotrophic factor expression in selected rat brain regions. Biol Psychiatry 55:708-714. CrossRef Medline

Roth TL, Sullivan RM (2005) Memory of early maltreatment: neonatal behavioral and neural correlates of maternal maltreatment within the context of classical conditioning. Biol Psychiatry 57:823-831. CrossRef Medline

Schiller D, Levy I, Niv Y, LeDoux JE, Phelps EA (2008) From fear to safety and back: reversal of fear in the human brain. J Neurosci 28:11517-11525. CrossRef Medline

Sehlmeyer C, Schöning S, Zwitserlood P, Pfleiderer B, Kircher T, Arolt V, Konrad C (2009) Human fear conditioning and extinction in neuroimaging: a systematic review. PLoS One 4:e5865. CrossRef Medline

Shors TJ, Seib TB, Levine S, Thompson RF (1989) Inescapable versus escapable shock modulates long-term potentiation in the rat hippocampus. Science 244:224-226. CrossRef Medline

Sierra-Mercado D, Padilla-Coreano N, Quirk GJ (2011) Dissociable roles of prelimbic and infralimbic cortices, ventral hippocampus, and basolateral amygdala in the expression and extinction of conditioned fear. Neuropsychopharmacology 36:529-538. CrossRef Medline

Simon E, Bögels SM (2009) Screening for anxiety disorders in children. Eur Child Adolesc Psychiatry 18:625-634. CrossRef Medline

Somerville LH, Wagner DD, Wig GS, Moran JM, Whalen PJ, Kelley WM (2013) Interactions between transient and sustained neural signals support the generation and regulation of anxious emotion. Cereb Cortex 23:49-60. CrossRef Medline

Sotres-Bayon F, Quirk GJ (2010) Prefrontal control of fear: more than just extinction. Curr Opin Neurobiol 20:231-235. CrossRef Medline

Sotres-Bayon F, Sierra-Mercado D, Pardilla-Delgado E, Quirk GJ (2012) Gating of fear in prelimbic cortex by hippocampal and amygdala inputs. Neuron 76:804-812. CrossRef Medline

Spinelli S, Chefer S, Suomi SJ, Higley JD, Barr CS, Stein E (2009) Early-life stress induces long-term morphologic changes in primate brain. Arch Gen Psychiatry 66:658-665. CrossRef Medline

Squire LR, Stark CE, Clark RE (2004) The medial temporal lobe. Annu Rev Neurosci 27:279-306. CrossRef Medline

Talairach J, Tournoux P (1988) Co-planar stereotaxic atlas of the human brain. Stuttgart, Germany: Thieme.

Torrents-Rodas D, Fullana MA, Bonillo A, Caseras X, Andión O, Torrubia R (2013) No effect of trait anxiety on differential fear conditioning or fear generalization. Biol Psychol 92:185-190. CrossRef Medline

Tottenham N, Hare TA, Quinn BT, McCarry TW, Nurse M, Gilhooly T, Millner A, Galvan A, Davidson MC, Eigsti IM, Thomas KM, Freed PJ, Booma ES, Gunnar MR, Altemus M, Aronson J, Casey BJ (2010) Prolonged institutional rearing is associated with atypically large amygdala volume and difficulties in emotion regulation. Dev Sci 13:46-61. CrossRef Medline

Tottenham N, Hare TA, Millner A, Gilhooly T, Zevin JD, Casey BJ (2011) Elevated amygdala response to faces following early deprivation. Dev Sci 14:190-204. CrossRef Medline

Uchida S, Hara K, Kobayashi A, Funato H, Hobara T, Otsuki K, Yamagata H, McEwen BS, Watanabe Y (2010) Early life stress enhances behavioral vulnerability to stress through the activation of REST4-mediated gene transcription in the medial prefrontal cortex of rodents. J Neurosci 30: 15007-15018. CrossRef Medline

Wager TD, van Ast VA, Hughes BL, Davidson ML, Lindquist MA, Ochsner KN (2009) Brain mediators of cardiovascular responses to social threat, part II: prefrontal-subcortical pathways and relationship with anxiety. Neuroimage 47:836-851. CrossRef Medline

Zeanah CH, Egger HL, Smyke AT, Nelson CA, Fox NA, Marshall PJ, Guthrie D (2009) Institutional rearing and psychiatric disorders in Romanian preschool children. Am J Psychiatry 166:777-785. CrossRef Medline 